\title{
Trend of epidemiological indicators of leprosy in an endemic state of the Amazon region
}

\author{
Tendência dos indicadores epidemiológicos da hanseníase \\ em um estado endêmico da região amazônica \\ Tendencia de indicadores epidemiológicos de la lepra em \\ el estado endémico de la región amazónica
}

\author{
Maria Eduarda de Macedo Basso ${ }^{a}$ \\ Rosemary Ferreira de Andrade ${ }^{a}$ \\ Rodrigo Luís Ferreira da Silva ${ }^{\mathrm{b}}$
}

\section{How to cite this article:}

Basso MEM, Andrade RF, Ferrreira da Silva

RL. Trend of epidemiological indicators of leprosy in an endemic state of the Amazon region. Rev Gaúcha Enferm. 2021:42:e20190520. doi: https://doi. org/10.1590/1983-1447.2021.20190520
- Universidade Federal do Amapá (UNIFAP), Programa de Pós-Graduação em Ciências da Saúde. Macapá, Amapá, Brasil.

- Universidade do Estado do Pará (UEPA), Departamento de Ciências do Movimento Humano. Santarém, Pará, Brasil.

\section{ABSTRACT}

Objective: To characterize the temporal trend of epidemiological indicators of leprosy in the State of Amapá.

Method: Time series study, carried out in the Notifiable Diseases Information System. The indicators analyzed were: annual detection rate of new cases, detection rate of new cases in the population from 0 to 14 years old, rate of new cases with grade 2 of disability, proportion of new cases with grade 2 and proportion of new multibacillary cases, between 2005 and 2018. The analysis of the temporal evolution was made by linear regression.

Results: The detection rate of new cases and the rate of children under 15 years showed a decreasing trend. The rate of new cases with grade 2 of disability and the proportion of cases with grade 2 showed oscillation. The proportions of multibacillary remained constant.

Conclusion: The epidemiological indicators analyzed suggest active transmission and late diagnosis, signaling a possible hidden endemic disease.

Keywords: Leprosy. Epidemiology. Temporal distribution. Public health

\section{RESUM0}

Objetivo: Caracterizar a tendência temporal dos indicadores epidemiológicos da hanseníase no Estado do Amapá

Método: Estudo de série temporal, realizado no Sistema de Informação de Agravos de Notificação. Os indicadores analisados foram: taxa de detecção anual de casos novos, taxa de detecção de casos novos na populaçãa de 0 a 14 anos, taxa de casos novos com grau 2 de incapacidade, proporção de casos novos com grau 2 e proporção de casos novos multibacilares, entre 2005 e 2018 . A análise da evolução temporal foi feita por meio de regressão linear.

Resultados: A taxa de detecção de casos novos e a taxa em menores de 15 anos apresentaram tendência decrescente. A taxa de casos novos com grau 2 de incapacidade e a proporção de casos com grau 2 apresentaram oscilação. As proporções de multibacilares mantiveram-se constantes.

Conclusão: Os indicadores epidemiológicos analisados sugerem transmissão ativa e diagnóstico tardio, sinalizando uma possível endemia oculta.

Palavras-chave: Hanseníase. Epidemiologia. Distribuição temporal. Saúde pública.

\section{RESUMEN}

Objetivo: Caracterizar la tendencia temporal de los indicadores epidemiológicos de la lepra en el Estado de Amapá

Métodos: Estudio de series temporales realizado en el Sistema de Información de Enfermedades de Notificación. Los indicadores analizados fueron: tasa de detección anual de nuevos casos, tasa de detección de nuevos casos en la población de 0 a 14 años, tasa de nuevos casos com grado 2 de discapacidad, proporción de nuevos casos con grado 2 y proporción de nuevos casos multibacilares, entre 2005 y 2018. El análisis de la evolución temporal se realizó mediante regresión lineal.

Resultados: La tasa de detección de nuevos casos y la tasa de niños menores de 15 años mostraron una tendencia decreciente. La tasa de casos nuevos con discapacidad de grado 2 y la proporción de casos con grado 2 mostraron oscilación. Las proporciones de multibacilares se mantuvieron constantes

Conclusión: Los indicadores epidemiológicos analizados sugieren transmisión activa y diagnóstico tardío, lo que indica una posible lepra oculta.

Palabras clave: Lepra. Epidemiología. Distribución temporal. Salud pública. 


\section{口INTRODUCTION}

Leprosy, a disease with high disabling power and strong stigma, still remains an important health problem in several countries. Despite the significant reduction in new cases of the disease after the introduction of multidrug therapy (MDT) in the 1980s, the World Health Organization (WHO) points out that, in 2018,208,619 new cases of the disease were registered in the world, with a general detection coefficient of 2.74/100 thousand inhabitants. India, Brazil and Indonesia were responsible for $79.6 \%$ of these new cases $^{(1)}$.

Brazil, which currently occupies the uncomfortable second position in the world ranking in relation to the number of new cases of the disease, has been showing a gradual reduction in the incidence each year. However, in $2018,28,660$ new cases were reported in the country, with a general detection coefficient of 13.68/100 thousand inhabitants, being classified as highly endemic according to the Ministry of Health $(\mathrm{MH})$ reference parameters for this indicator ${ }^{(2-3)}$.

When analyzed by regions, the geographical distribution of the disease in Brazil shows unequal patterns, with a high concentration of new cases in the Midwest, North and Northeast regions when compared to the South and Southeast regions. In relation to the numbers of the disease in the North, in 2018,5,802 new cases were notified, being the second highest rate in the country among the regions, with 31.95/100 thousand inhabitants, classified, therefore, in a region with very high endemicity ${ }^{(3)}$.

In this epidemiological perspective of the distribution of the disease in Brazil, there is a greater number of new cases in poorer areas and regions of the country. Ineffective immune response, poor socioeconomic conditions and difficulty in accessing health services are related to greater susceptibility to the development of the disease ${ }^{(4)}$. As it predominantly affects people in poverty, leprosy is considered a neglected disease, with important barriers to its control and elimination, including in Brazil(2).

For a more effective confrontation in the fight against leprosy and other neglected diseases in Brazil, in 2011, the MH created the General Coordination of Leprosy and Diseases in Elimination (Coordenação Geral de Hanseníase e Doenças em Eliminação - (GHDE) with the objective of improving the response to a group of diseases in which the results of national programs were considered insufficient and incompatible with the capacity of the Unified Health System (Sistema Único de Saúde - SUS) to resolve these problems ${ }^{(2)}$.
In 2015, the United Nations (UN) published the 2030 Agenda, composed of a set of goals and objectives aimed at a sustainable transformation of the planet, in economic, social and environmental aspects. The 17 Sustainable Development Goals (SDGs) include actions in areas of crucial importance to humanity. Thus, leprosy was included in Objective 3, which aims to ensure a healthy life and the promotion of well-being for all, with the proposed goal of "by 2030, ending the epidemics of AIDS, tuberculosis, malaria and neglected tropical diseases, and combat hepatitis, waterborne diseases, and other communicable diseases" ${ }^{\prime \prime(5)}$.

The WHO Global Strategy for Leprosy 2016-2020 aimed to further reduce the global burden of the disease, with the main goals by 2020 to eliminate new cases with physical disabilities in children, reduce new cases with grade 2 of physical disability to less than one case per million inhabitants and actions that restrain the discrimination against those affected ${ }^{(4)}$. In line with the Global Strategy for Leprosy 2016-2020, but adapted to the Brazilian reality, the Ministry of Health elaborated the National Strategy for Coping with Leprosy 2019-2022, with the innovative proposal of working with all Brazilian municipalities through different methodologies facing the heterogeneous patterns of endemicity existing in the regions and municipalities of the country(6).

In this 2019-2022 National Strategy, the municipalities were divided into three groups according to their epidemiological and operational characteristics. In group 1, municipalities with no new cases between 2013 and 2017 were included; in group 2, the municipalities with a detection rate $<10$ cases $/ 100,000$ inhabitants and, in group 3, the municipalities with a detection rate $\geq 10$ cases $/ 100,000$ inhabitants. The goals adapted for Brazil to be achieved by 2022 were: to reduce to 30 the number of children with grade 2 physical disability; reduce the rate of new cases of leprosy with grade 2 physical disability to 8.83 cases/ 1 million and implement channels in all states to record discriminatory practices against people affected by leprosy and their families ${ }^{(6)}$. From the 16 municipalities in the State of Amapá, 13 were included in group 3.

More than three decades after the first leprosy elimination proposal was prepared, Brazil still has difficulties in controlling the disease. Every year new cases are registered in the country with visible disabilities in the diagnosis and new cases in children, especially in regions and municipalities that have suffered from the problem of the endemic disease for decades. Thus, it is reaffirmed the importance of indicators for monitoring and more effective measures for fighting leprosy in Brazil. 
Thereby, the analysis of the indicators assumes an important role in monitoring and directing health actions more effectively in the fight against leprosy, as well as pointing out the possible difficulties and failures in the health services offered (2). In this context, it is highlighted the relevance of the nursing professional, who works directly in caring for affected patients, participates in the diagnosis, monitoring, treatment, prevention of disabilities, referral and surveillance, and plays a fundamental role in the construction and improvement of epidemiological and operational indicators of leprosy.

Despite advances in the control of leprosy in the country, the disease still represents an important challenge for public health authorities and, in view of the epidemiological picture of the endemic disease in the State of Amapá, it was felt the need for this scientific work. In view of the observations that justify this research, the main problem of the study can be defined as follows: what is the temporal trend of leprosy in the State of Amapá from the assessment of its epidemiological indicators, from 2005 to 2018 ? The objective of the study was to characterize the temporal trend of epidemiological indicators of leprosy in the State of Amapá between 2005 and 2018 and to compare it with that of Brazil.

\section{$\square$ METHODS}

The State of Amapá, located in the extreme north of Brazil, is divided into 16 municipalities, and occupies an area of $142,828,521 \mathrm{~km}^{2}$, being the 18th largest state in Brazil. It corresponds to $1.65 \%$ of the area of Brazil and $3.71 \%$ of the North region. The estimated population was 829,494 for the year 2018 and demographic density of 5.58 inhabitants $\mathrm{km}^{2}$.

This is a epidemiological time series study, retrospective and documentary, carried out based on the records of new cases of leprosy from the 16 municipalities in the State of Amapá. Data collection was carried out in July and August 2017 and updated in June 2020, in the Notifiable Diseases Information System (Sistema de Informação de Agravos de Notificação - Sinan), coordinated by the Leprosy Control Program, the Epidemiological Surveillance Center of the Superintendence of Health Surveillance in the State of Amapá.

The epidemiological indicators evaluated in the research were built from the new cases of leprosy notified between the years 2005 and 2018 of patients residing in the State of Amapá at the time of diagnosis. The period of the historical series of the study included the analysis of the rates and proportions of the last 14 years, allowing researchers to perceive the trend of the researched event, except for the year 2019, as it is still in the system as preliminary data.

For this research, five epidemiological indicators were analyzed. The first was the annual detection rate of new cases of leprosy per 100 thousand inhabitants, which measures the force of the morbidity, magnitude and tendency of the endemic disease. The indicator calculation was realized as follows: number of new confirmed cases of leprosy in residents, divided by the total resident population in the given period, multiplied by 100 thousand. It has the following reference parameters: hyperendemic: $>40.0$ cases/100 thousand inhab.; very high: 20.00 to 39.99/100 thousand inhab.; high: 10.00 to 19.99/100 thousand inhab.; medium: 2.00 to 9.99/100 thousand inhab.; low: $<2.00 / 100$ thousand inhab. (2).

The second indicator, the annual detection rate of new cases of leprosy in the population aged 0 to 14 , per 100 thousand inhabitants, has the utility of measuring the recent transmission force of the endemic and its tendency. The indicator was calculated by dividing the number of new cases of leprosy in children under 15 years old, divided by the population aged 0 to 14 years old resident in the given period, multiplied by 100 thousand. It presents the following parameters: hyper-endemic: $\geq 10.00 / 100$ thousand inhab.; very high: 5.00 to $9.99 / 100$ thousand inhab.; high: 2.50 to 4.99 per 100 thousand inhab.; medium: 0.50 to 2.49 per 100 thousand inhab.; low: $<0.50$ per 100 thousand inhabitants ${ }^{(2)}$.

The third indicator was the rate of new cases of leprosy with grade 2 of physical disability at the time of diagnosis per 1 million inhabitants. This indicator assesses the deformities caused by leprosy in the general population, compares it with other disabling diseases and signals a late diagnosis of the endemic disease. The calculation is performed by dividing the number of new cases with grade 2 of physical disability in the diagnosis in the year of assessment by the population living in the same place and year of assessment, multiplied by 1 million. It does not specify parameters.

The fourth indicator studied was the proportion of leprosy cases with grade 2 of physical disability at the time of diagnosis. Its function is to assess the effectiveness of activities for timely and/or early case detection. Calculation of the indicator: number of new confirmed cases of leprosy with grade 2 of physical disability in residents, divided by the number of new cases with grade of physical disability assessed in the same place and period, multiplied by 100 . Its reference parameters are as follows: high: $\geq 10 \%$; medium: 5 to $9.9 \%$; low: $<5 \%$. 
Finally, was analyzed the fifth indicator, the proportion of new multibacillary cases. Its usefulness is to evaluate cases at risk of developing complications and to guide the correct replenishment of MDT. The indicator construction was made by dividing the number of new cases of multibacillary leprosy in the same place and period, by the total number of new cases, multiplied by 100 . It does not specify parameters.

The indicators selected for this research are recommended in the WHO Global Strategy for Leprosy 2016-2020(4) and in the Guidelines for the surveillance, care and elimination of leprosy as a public health problem in Brazil of $\mathrm{MH}^{(2)}$, considered priorities for evaluation and monitoring the endemic. The calculation and interpretation of the indicators took place according to the parameters for leprosy control recommended by the $\mathrm{MH}^{(2)}$.

The data were organized in Excel spreadsheets, which were also used for graphical representations and for calculating indicators. The temporal evolution was assessed using linear regression models, considering the year as an independent variable and each indicator as a dependent variable. These models made it possible to assess whether there was an increasing, decreasing or constant linear trend in the evolution of the indicators over time. Are presented the standardized beta regression coefficient ( $\beta$ ), the coefficient of determination $R^{2}$ and the $p$-value significance. The evolutions were considered statistically significant when the $p$-value was less than 0.05 ( $p<0.05$ - 5\% significance level). The analyses were performed using the Statistical Package for the Social Sciences (SPSS) software, version 22.

Although this study was carried out with secondary data, in which there are no subjects participating in the research, it was submitted to the Research Ethics Committee of the
Universidade Federal do Amapá (Unifap) and approved under statement No.2,073,529.

\section{RESULTS}

In the period considered for the study, a total of 1,988 new cases of leprosy were reported in the State of Amapá, with 171 (8.6\%) new cases in the population aged 0 to 14 years and 132 (6.6\%) new cases with grade 2 of physical disability in the diagnosis.

It was found that the annual detection rate of new cases in the state decreased from 2011, going from very high in 2012 to high endemicity between 2013 and 2018 (Table 1).

In the annual detection rate of new cases in the population up to 14 years old, in Amapá, there was a variation in the data during the study period, being classified as high endemicity in 2018 (Table 1).

The proportion of new cases with grade 2 of physical disability in the diagnosis in the state showed an important oscillation in the researched period, classified as medium endemicity in the last year of the evaluated temporal frame (Table 1).

Regarding the analysis of the temporal trends of the indicators, it was found that the annual detection rate of new cases of leprosy showed a significant downward trend between 2005 and 2018, both in Brazil $\left(\beta=-0.960 ; R^{2}=0.922\right.$; $p<0.001)$ as in the State of Amapá ( $\beta=-0.833 ; R^{2}=0.694$; $p<0.001$ ) (Figure 1).

As for the rate of new cases of leprosy in the population up to 14 years old, the trend was significantly decreasing in Brazil $\left(\beta=-0.944 ; R^{2}=0.890 ; p<0.001\right)$ and also decreasing in the State of Amapá ( $\beta=-0.576 ; R^{2}=0.332 ; p=0.031$ ), but less defined ( $R^{2}$ much lower than in Brazil) (Figure 2$)$.

\section{Rate of new cases of leprosy per 100 thousand inhabitants}

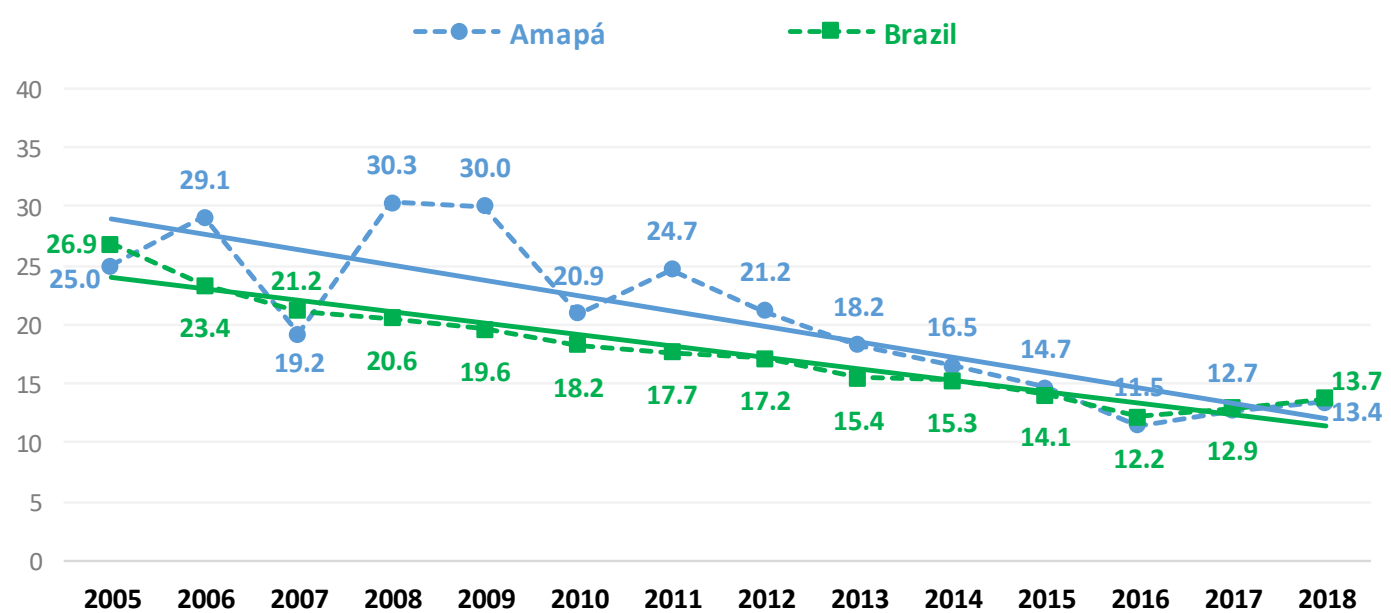

Figure 1 - Annual detection rate of new cases of leprosy per 100 thousand inhabitants, 2005 to 2018, State of Amapá and Brazil Source: Secondary data - SINAN, 2020. 
Table 1 - Evolution of epidemiological indicators of leprosy and their respective classifications, in the period 2005 - 2018. State of Amapá, 2020

\begin{tabular}{lcccccc} 
YEAR & $\begin{array}{c}\text { Annual detection rate of } \\
\text { new cases of leprosy } \\
(\mathbf{1 0 0} \text { thousand inhab.) }\end{array}$ & $\begin{array}{c}\text { Rate of new cases in the } \\
\text { population aged } \mathbf{0} \text { to } \mathbf{1 4} \\
\text { years (100 thousand inhab.) }\end{array}$ & $\begin{array}{c}\text { Proportion of cases with grade } \\
\mathbf{2} \text { of physical disability } \\
\text { in the diagnosis }\end{array}$ \\
\cline { 2 - 6 } & Rate & Classification* & Rate & Classification* & Proportion & Classification* \\
\hline 2005 & 25.0 & Very high & 4.3 & High & $6.5 \%$ & Medium \\
2006 & 29.1 & Very high & 5.8 & Very high & $5.3 \%$ & Medium \\
2007 & 19.2 & High & 5.0 & Very high & $9.6 \%$ & Medium \\
2008 & 30.3 & Very high & 9.6 & Very high & $8.4 \%$ & Medium \\
2009 & 30.0 & Very high & 8.2 & Very high & $4.9 \%$ & Low \\
2010 & 20.9 & Very high & 7.2 & Very high & $6.8 \%$ & Medium \\
2011 & 24.7 & Very high & 7.5 & Very high & $8.1 \%$ & Medium \\
2012 & 21.2 & Very high & 5.2 & Very high & $5.7 \%$ & Medium \\
2013 & 18.2 & High & 2.5 & High & $10.1 \%$ & High \\
2014 & 16.5 & High & 5.2 & Very high & $4.2 \%$ & Low \\
2015 & 14.7 & High & 5.2 & Very high & $15.6 \%$ & High \\
2016 & 11.5 & High & 2.4 & Medium & $6.8 \%$ & Medium \\
2017 & 12.7 & High & 2.8 & High & $6.1 \%$ & Medium \\
2018 & 13.4 & High & 2.9 & High & $7.8 \%$ & Medium \\
\hline
\end{tabular}

Source: Secondary data - SINAN, 2020.

*Classification used by the Ministry of Health ${ }^{(2)}$

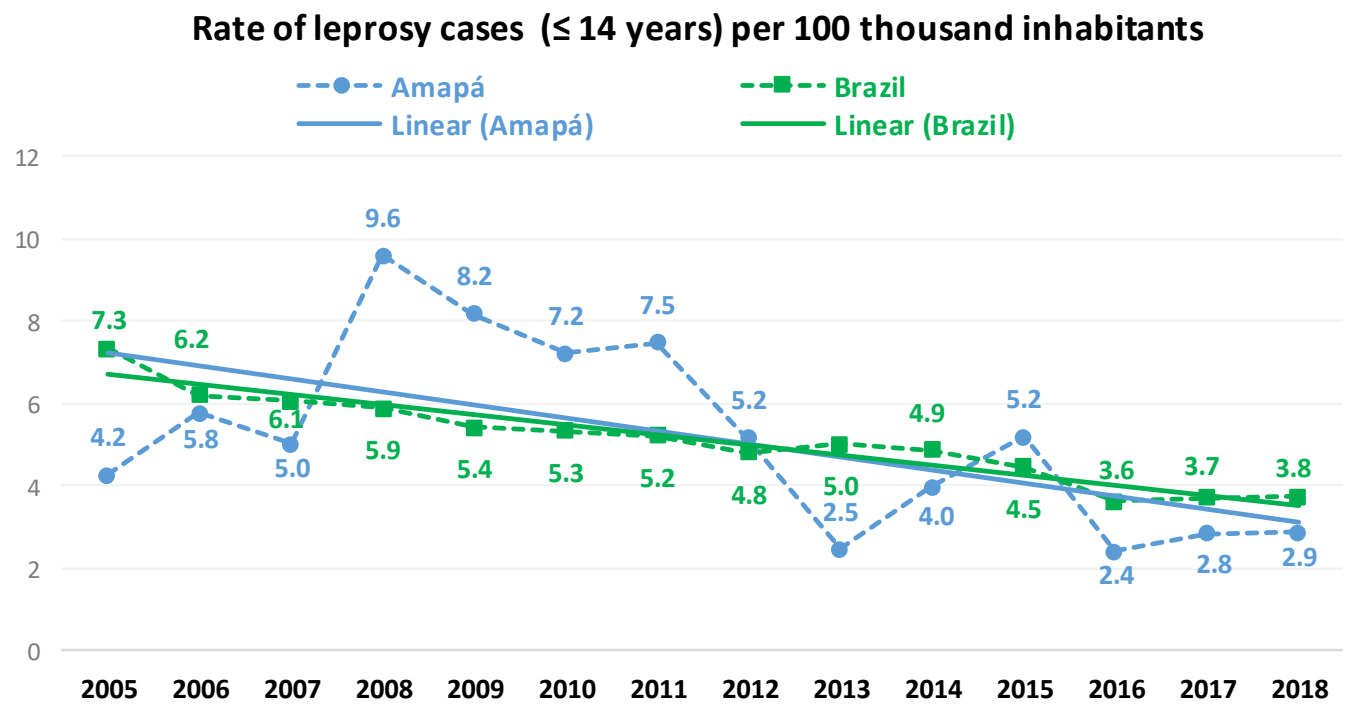

Figure 2 - Annual detection rate of new cases of leprosy in the population up to 14 years old, per 100 thousand inhabitants, 2005 to 2018, State of Amapá and Brazil Source: Secondary data - SINAN, 2020. 
The rate of new cases of leprosy with grade 2 of physical disability at the time of diagnosis per 1 million inhabitants was significantly decreasing in Brazil $\left(\beta=-0.860 ; R^{2}=0.739 ; p\right.$ $<0.001)$. In Amapá, unlike the national data, there is a large oscillation, although they also point to a slight decrease in the rate at the end of the researched temporal frame. However, even showing this decrease, the rate still does not show a significant reduction ( $\beta=-0.346 ; R^{2}=0.120 ; p=0.226$ ) (Figure 3).

The proportion of cases with grade 2 of physical disability at the time of diagnosis remained constant in Brazil $(\beta=$
$0.434 ; R^{2}=0.188 ; p=0.121$ ), while in Amapá $\left(\beta=0.266 ; R^{2}=\right.$ $0.071 ; p=0.358$ ), there was an important oscillation of this proportion throughout the evaluated series. Although the data points out to an increase in the proportions in Brazil and Amapá, they were not significant (Figure 4).

Regarding the proportion of new multibacillary cases, a significantly increasing trend was found in Brazil ( $\beta=0.990$; $\left.R^{2}=0.981 ; p<0.001\right)$. In Amapá $\left(\beta=0.339 ; R^{2}=0.115 ; p=\right.$ $0.235)$, this proportion has remained constant over the years analyzed (Figure 5).

\section{Rate of new cases of leprosy with grade 2 of physical disability per 1 million inhabitants}

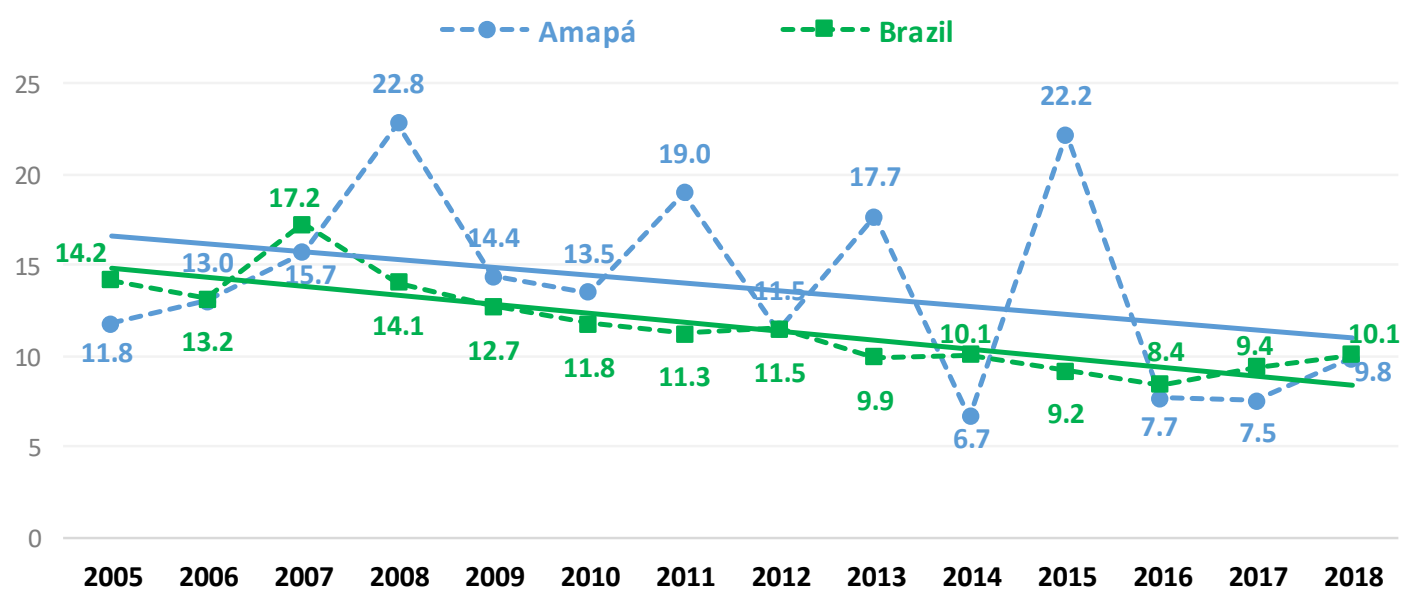

Figure 3 - Rate of new cases of leprosy with grade 2 of physical disability at the time of diagnosis per 1 million inhabitants, 2005 to 2018, State of Amapá and Brazil Source: Secondary data - SINAN, 2020.

\section{Proportion of new cases of leprosy with grade 2 of physical disability}

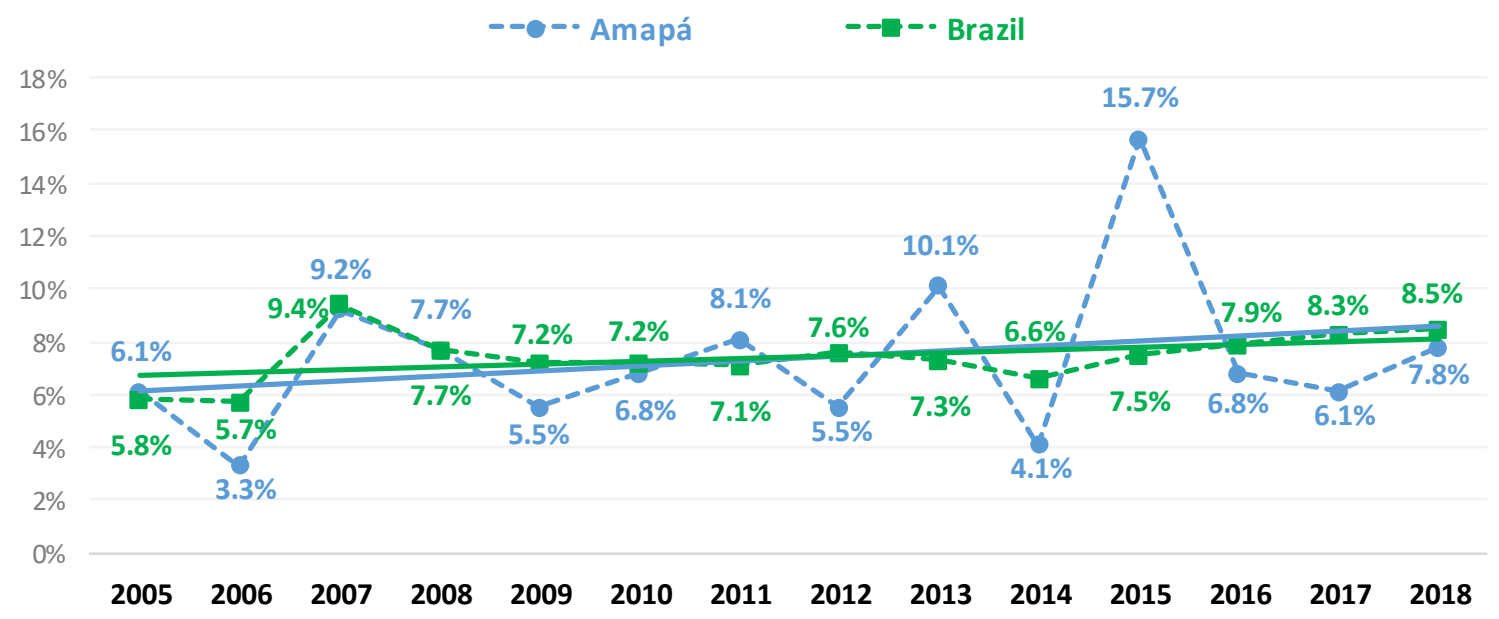

Figure 4 - Proportion of leprosy cases with grade 2 of disability at the time of diagnosis, 2005 to 2018 , State of Amapá and Brazil

Source: Secondary data - SINAN, 2020. 


\section{Proportion of new multibacillary cases}

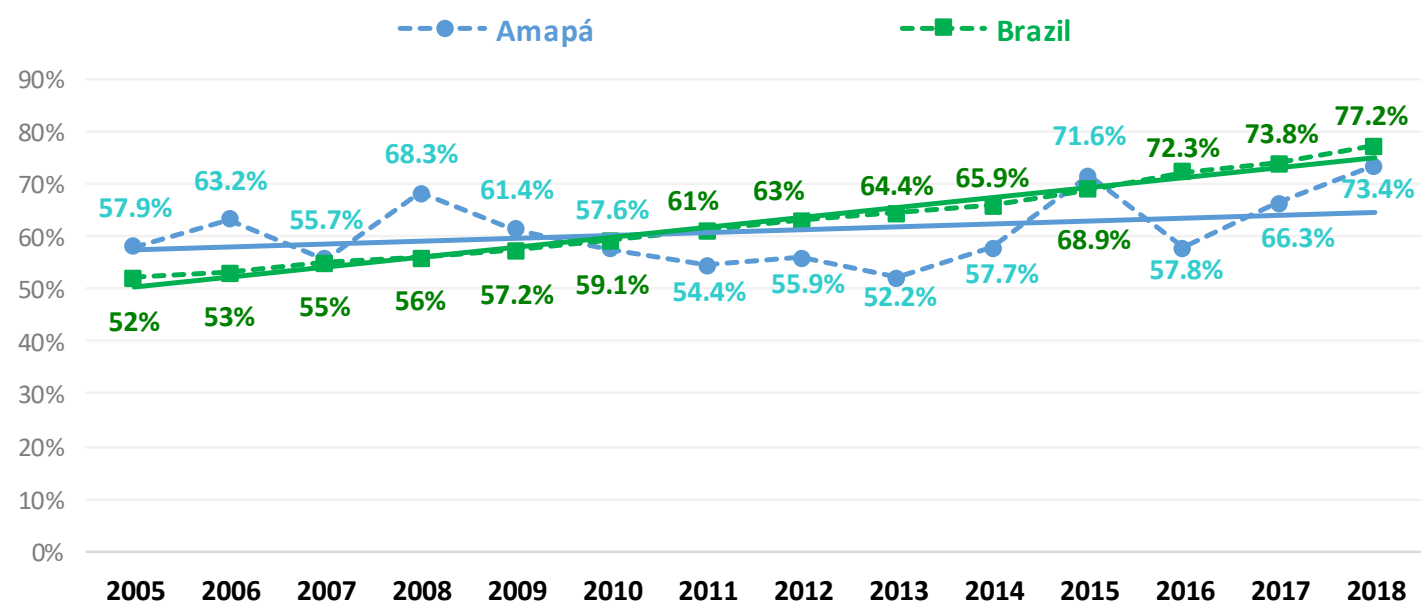

Figure 5 - Proportion of new multibacillary cases, 2005 to 2018, State of Amapá and Brazil Source: Secondary data - Sinan, 2020.

\section{DISCUSSION}

The trend towards a reduction in the detection rate of new cases observed in the State of Amapá suggests a decrease in the force of the morbidity and magnitude of the endemic disease. However, even though the temporal trend has shown a significant reduction, it is important to highlight the rate increase in the last two years evaluated, both in Amapá and in Brazil. In Amapá, this indicator went from being very high endemicity (20.00 to 39.99/100 thousand inhabitants) in 2005 to high endemicity (10.00 to 19.99/100 thousand inhabitants) in 2018, still showing the severity of the problem in the state ${ }^{(2)}$.

This trend of downward in the rate of new cases seen in the State of Amapá has accompanied the downward trend in new cases in Brazil and in the Brazilian states over the past decade. A study carried out in the State of Paraíba ${ }^{(7)}$ found this downward slope, as well as in the State of Tocantins ${ }^{(8)}$ and in the city of Fortaleza(CE) ${ }^{(9)}$. A research realized in 692 municipalities in the states of Mato Grosso, Tocantins, Rondônia, Pará and Maranhão also indicated a decreasing trend in the rate of new cases $^{(10)}$.

According to data from the $\mathrm{MH}$, since 2005, all Brazilian states have shown a reduction in their general detection coefficient ${ }^{(3)}$. And, in addition, trend analysis research also points to the decline in the general detection coefficient of new cases in Brazilian states and municipalities. In fact, the annual detection rate for new cases is an important indicator for monitoring the progress of leprosy elimination as a public health problem. However, it is known that the rate of new cases should not be assessed in isolation, as it may be influenced by failures in the operational capacity of health services to early diagnose new cases of the disease in endemic areas ${ }^{(11)}$.

Authors ${ }^{(8,12)}$ stated that the decrease in the number of new cases in endemic countries should be carefully assessed, because leprosy is a chronic, stable disease with a long incubation period and, therefore, a decrease in the detection rate may be related to the lack of diagnosis and the increase of hidden prevalence, and not to the real decrease in the incidence of cases.

In this context, it should be noted that the significant reduction in the prevalence of leprosy after the implantation of MDT was not accompanied by a significant decrease in the rate of detection of new cases, reinforcing the hypothesis that it reduced the prevalence, but did not prevent the transmission of disease, resulting in the loss of interest and expertise about the issue by health professionals ${ }^{(13)}$. In addition, researches identified the presence of subclinical infection in household contacts ${ }^{(14-15)}$, showing this scenario of probable underreporting in the country.

Despite the downward trend in the rate of new cases in Brazil, in 2016, the State of Tocantins, surprisingly, was the only Brazilian state to show an expressive increase in the rate of new cases of leprosy in the country. It went from a general detection coefficient of 58.08/100 thousand inhabitants in 2015 to $88.13 / 100$ thousand inhabitants in 2016, reaching the first place in the number of new cases among Brazilian states $^{(3)}$. The explanation for this significant increase in the detection rate in the State of Tocantins is in the creation of the "Palmas Free from Leprosy" program, a project of the Municipal Health Department, carried out in 2016, having as 
main strategy the training of multidisciplinary teams within the Basic Health Units. This action provided to professionals a practical training and greater security in making the diagnosis of the disease ${ }^{(16)}$.

The example of Tocantins showed that the decrease in the rate of new cases is probably related to the decrease in the diagnosis of the disease, especially in endemic areas that, therefore, training and qualification is necessary for the diagnosis of hidden cases. The program held in Palmas gained prominence in the $\mathrm{WHO}$ and served as a model for the MH to implement the project "Innovative Approaches to Intensify Efforts for a Brazil Free from Leprosy", carried out for three years (2017-2019), in 20 municipalities of the states of Maranhão, Mato Grosso, Pará, Pernambuco, Piauí and Tocantins ${ }^{(17)}$.

Being aware of the complexity of analyzing this indicator, such considerations point out that the tendency for decreasing the rate of new cases of leprosy in Amapá, as well as in other states, is possibly related to the decrease in the diagnosis of the disease and underreporting. Thus, the increase in the rate of new cases in Brazil, in 2017 and 2018, can be justified by the operationalization of the trainings from the project "Innovative Approaches to Intensify Efforts for a Brazil Free from Leprosy", which emphasized the practical training for primary care professionals regarding diagnosis, treatment and prevention of disability ${ }^{(17)}$.

The rate of new cases of leprosy in the population up to 14 years old is an important indicator that signals active transmission of the infection, suggesting early exposure and deficiency in disease surveillance and control ${ }^{(4,18)}$. In the present study, linear regression pointed out to a downward trend for this indicator in Brazil and in Amapá, however, it is worth noting the increase in this rate in the last two years of the analyzed series, with the classification of high endemicity in 2018, in the state.

Research carried out in the State of Mato Grosso ${ }^{(19)}$ analyzed the trend of new cases of leprosy in children under 15 years old, observing a decreasing behavior of this indicator between the years 2001 and 2013 in that state, however it remained hyper endemic, which indicates, therefore, maintenance of the recent transmission of the endemic and late detection. Studies carried out in the city of Fortaleza (CE) ${ }^{(9)}$ and in the State of Tocantins ${ }^{(8)}$ showed a trend towards stability of this indicator in their researched historical series. In view of these results, the authors state that this epidemiological behavior of leprosy observed in children under 15 years of age can be explained by the persistence of active focus of transmission resulting from circulating bacilli in undiagnosed multibacillary cases.
A study carried out in the State of Pará, with 1,592 students ${ }^{(14)}$, identified $4 \%$ of new cases of leprosy in the sample and $9.4 \%$ in their household contacts. Among diagnosed students, paucibacillary cases predominated (71.4\%), while, among contacts, the majority were multibacillary (62.5\%). According to the study's researchers, there is a high rate of undiagnosed cases in the Amazon region, with persistence of the transmission chain and an early exposure of children to the bacillus. Another time trend study ${ }^{(20)}$ verified a decrease in new cases in children under 15 in Brazil and in all regions of the country, between 2001 and 2016. However, despite this decrease, the authors found that the North Region and the State of Amapá maintained, respectively, the average hyperendemic and very high for this indicator, considering the analyzed period, which indicates the continuity of active focus of disease transmission.

The presence of new cases of leprosy in children reinforces the need to carry out specific actions and programs in the search for new cases in this population. In this sense, in 2013, the $\mathrm{MH}$ initiated the first National Campaign for Leprosy, Verminosis and Trachoma, in schoolchildren aged 5 to 14 , from public schools in selected municipalities.

In the first edition of the campaign, 852 municipalities participated, including the city of Macapá-AP. This innovative campaign in the school environment has proven to be an effective strategy and has already made it possible to diagnose hundreds of new cases in children across Brazil, including in Amapá(21). Despite the decreasing trend in the rate of new cases of leprosy in children in the State of Amapá, it is observed, the presence of new cases in this population in all the years analyzed throughout the time, with an increase in the rate in 2017 and 2018, and high endemicity rating in the last year for this indicator.

The presence of new cases with grade 2 of physical disability at the time of diagnosis is an important indicator that signals the effectiveness of timely detection activities and the early diagnosis ${ }^{(2)}$. In leprosy, late diagnosis increases the chances of injury to peripheral nerves and the appearance of physical disabilities, with a significant impact on the bodily functionality and work capacity of the affected people, with repercussions on psychological and social aspects, being also responsible for stigma, prejudice, self-segregation and changes in body image ${ }^{(22)}$.

One of the goals of the Global Strategy for Leprosy 2016$2020^{(4)}$ is to reduce new cases with grade 2 of physical disability to less than one case per 1 million inhabitants. In this sense, the reduction of cases diagnosed with physical disability has become a priority for the Ministry of Health and constituted a key indicator in the elaboration of the 
epidemiological and operational groups of the National Strategy for Coping with Leprosy 2019-2022 $2^{(6)}$. In the national strategy, the target was adapted to 8.83 cases. The addition of this indicator associated with the proportions of grade 2 cases suggests that the diagnosis is occurring late.

In Amapá, the rate of new cases with grade 2 per 1 million inhabitants showed an important oscillation in the historical series evaluated. In this context, it is highlighted that the referred indicator does not follow the downward trend observed in the rate of new cases in the state (Figure 1). In addition, the rate of $9.8 \%$, seen in the last year researched, is still far from the WHO target, however it approaches the target proposed by the National Strategy.

In the proportion of new cases with grade 2 of disability in the diagnosis, there was also a large oscillation in the period. In 2015, for example, Amapá had the second highest proportion of new cases with grade 2 in the diagnosis, only behind Rio Grande do Sul that year. In the following years, there was a decline, however, in 2018, it remained at a proportion of $7.8 \%$. These findings demonstrate the severity of the problem in the state and reinforce the hypothesis of late diagnosis and probable hidden endemic disease.

In addition, on the world scenario, of the nearly 209 thousand new cases of leprosy in 2018,11,322 new cases with grade 2 of disability were recorded at the time of diagnosis among the populations of the 159 countries that reported new cases to WHO. In Brazil, were reported 2,109 new cases with grade 2 of disability in the diagnosis and a proportion of $8.5 \%{ }^{(22)}$. Thus, WHO reinforces the importance of countries maintaining early detection of cases as the main strateg ${ }^{(4)}$. A time series study conducted in the State of Paraíba found a steady trend in new cases with grade 2 of disability ${ }^{(23)}$. However, in the state of Maranhão, a recent research ${ }^{(24)}$ pointed out an increasing trend in new cases with grade 2 . Other studies ${ }^{(6-8)}$ demonstrated a trend towards stability for this indicator, signaling delay in diagnosis and hidden prevalence.

Thereby, even with the significant increase in the coverage of primary care in the State of Amapá in recent years, the data obtained suggest that basic health units still find it difficult to diagnose and treat cases in the initial forms of the disease. Thus, strategies that can influence the improvement of this indicator include early detection, the commitment of health teams in the active search for cases and strict monitoring of household contacts due to the long period of disease incubation ${ }^{(7,12)}$.

Regarding the proportion of new multibacillary cases in Amapá, the predominance and stability of MB cases was found in the study, reinforcing the hypothesis of delayed diagnosis and maintenance of the transmission dynamics(4).
On the other hand, it is known that, depending on the analyzed epidemiological location and context, it is possible that an increasing trend of new MB cases points to a situation of control and reduction of the transmission of the endemic disease.

In South Korea ${ }^{(25)}$, a time trend study pointed to a decrease in the prevalence and rate of new cases overall and in children in the country, with an increase in the proportion of new MB cases and a constant increase in the average age of newly detected cases, indicating infection acquired many years ago. At the same time, there was a strict control of operational indicators, with an improvement in the population's standard of living and greater access to health services.

In this context, in the Brazilian scenario, since 2003, there has been a predominance and an increasing trend of new MB cases in the country. In 2018, in Brazil, this proportion was 77.2\%. However, unlike the South Korean epidemiological behavior, this analysis, perhaps, still does not apply to the reality of Brazil and the State of Amapá. In addition to the presence of new cases in children and new cases with disabilities, important operational indicators, such as, for example, the proportion of cure and examination of contacts, remain with regular parameters in the country ${ }^{(3)}$. In the social context, Brazil is still characterized by great social inequalities, with an expressive part of the population in social vulnerability and difficulties in accessing health services.

In view of the above, it appears that leprosy still remains as an aggravation of great relevance for public health in most Brazilian states and in Brazil. The knowledge of epidemiological indicators and their trends is important so that health professionals, especially those inserted in primary care, may understand the behavior of the endemic and direct their actions in the search for new cases of the disease and in the prevention of disabilities, interrupting the epidemiological chain of transmission.

It stands out as a limitation in this research the use of secondary data, taking into account possible standardization failures in the collection of information by health professionals and in filling in the variables in the system, which can influence the quality of the recorded data.

\section{CONCLUSION}

Within the State of Amapá, the epidemiological indicators evaluated indicate a possible hidden prevalence of the disease in the state, because, despite the decreasing trend in the annual detection rate of new cases and the rate of new cases in children, it was verified an instability of rate of new cases with grade 2 of disability per 1 million inhabitants and the proportion of new cases with grade 2 of disability 
in the diagnosis and a stability of the proportion of new multibacillary cases, reflecting the operational difficulties related to early diagnosis.

The results found indicate difficulty in the activities of early detection of the disease and the permanence of the epidemiological chain of transmission. Therefore, the decreasing behavior observed in the rate of new cases is possibly related to a decrease in the operational capacity to diagnose hidden cases. In this sense, government agencies are responsible for implementing their respective plans, elaborated in 2019, in line with the National Leprosy Coping Strategy (2019-2022), in an effort to control the disease and achieve the goals proposed by the $\mathrm{MH}$.

It is suggested the realization of further studies to monitoring the evolution of leprosy in Amapá based on its indicators, mainly for monitoring the rate of grade 2 per 1 million inhabitants and the proportion of grade 2 in the diagnosis, which showed a significant oscillation in the researched period. Finally, the realization of a time frame for the analysis of operational indicators, such as the proportion of cure and the number of contacts examined, and the proportion of those assessed as to the grade of disability at discharge and cure, may further collaborate in understanding the behavior of leprosy in Amapá.

\section{REFERENCES}

1. World Health Organization (CH). Global leprosy update, 2018: moving towards a leprosy-free world. Weekly Epidemiol Rec. 2019 [cited 2019 Aug 19];94(35/36):389-412. Available from: https://apps.who.int/iris/bitstream/ handle/10665/326775/WER9435-36-en-fr.pdf?ua=1

2. Ministério da Saúde (BR). Secretaria de Vigilância em Saúde. Departamento de Vigilância das Doenças Transmissíveis. Diretrizes para vigilância, atenção e eliminação da hanseníase como problema de saúde pública: manual técnicooperacional. Brasília: Ministério da Saúde; 2016 [citet 2019 Sep 15]. Available from: http://www.credesh.ufu.br/sites/credesh.hc.ufu.br/arquivos/diretrizeseliminacao-hanseniase-4fev16-web.pdf

3. Ministério da Saúde (BR). Secretaria de Vigilância Sanitária. Sistema de Informação de Agravos de Notificação Taxa de detecção geral de hanseníase por 100.000 habitantes, Estados e regiões, Brasil, 1990 a 2018. Brasília; 2019 [cited 2019 Jul 25]. Available from: https://portalarquivos2.saude.gov.br/images/ pdf/2019/julho/17/Casos-novos-de-hansen--ase-por-estados-e-regi--es-Brasil--1990-a-2018.pdf

4. Organização Mundial da Saúde (CH). Estratégia global para a hanseníase 20162020: aceleração rumo a um mundo sem hanseníase. Geneva: OMS; 2016 [cited 2017 Apr 12]. Available from: https://apps.who.int/iris/bitstream/hand le/10665/208824/9789290225201-pt.pdf? sequence $=17$

5. Nações Unidas (BR). Transformando nosso mundo: a Agenda 2030 para 0 Desenvolvimento Sustentável. Brasília; 2016 [cited 2020 Jun 18]. Available from: http://svs.aids.gov.br/dantps/acesso-a-informacao/acoes-e-programas/ ods/publicacoes/transformando-nosso-mundo-a-agenda-2030-para-0desenvolvimento-sustentavel.pdf
6. Ministério da Saúde (BR). Secretaria de Vigilância em Saúde. Departamento de Doenças de Condições Crônicas e Infecções Sexualmente Transmissíveis. Estratégia Nacional para Enfrentamento da Hanseníase 2019-2022. Brasília: Ministério da Saúde; 2020 [cited 2019 Aug 20]. Available from: http://www.aids.gov.br/pt-br/pub/2020/ estrategia-nacional-para-enfrentamento-da-hanseniase-2019-2022

7. Brito KKG, Andrade SSC, Santana, EMF, Peixoto VB, Nogueira JA, Soares MJGO. Epidemiological analysis of leprosy in an endemic state of northeastern Brazil. Rev Gaúcha Enferm. 2015;36(esp):24-30. doi: https://doi.org/10.1590/19831447.2015.esp.55284

8. Monteiro LD, Martins-Melo FR, Brito AL, Lima MS, Alencar CH, Heukelbach J. Tendências da hanseníase no Tocantins, um estado hiperendêmico no norte do Brasil, 2001-2012. Cad Saúde Pública. 2015;31(5):971-80. doi: https://doi. org/10.1590/0102-311X00075314

9. Brito AL, Monteiro LD, Ramos Júnior AN, Heukelbach J. Temporal trends of leprosy in a Brazilian state capital in Northeast Brazil: epidemiology and analysis by joinpoints, 2001 to 2012. Rev Bras Epidemiol. 2016;19(1):194-204. doi: https://doi.org/10.1590/1980-5497201600010017

10. Freitas LRS, Duarte EC, Garcia LP. Trends of main indicators of leprosy in Brasilian municipalites with high risk of leprosy transmission, 2001-2012. BMC Infect Dis. 2016;16:472. doi: https://doi.org/10.1186/s12879-016-1798-2

11. Chaptini C, Marshman G. Leprosy: review on elimination, reducing the disease burden, and future research. Lepr Rev. 2015;86:307-15.

12. Salgado CG, Barreto JG, da Silva MB, Frade MAC, Spencer JS. What do we actually know about leprosy worldwide? Lancet Infect Dis. 2016;16(7):778. doi: https://doi.org/10.1016/S1473-3099(16)30090-1

13. Virmond MCL. Leprosy after elimination [editorial]. Hansen Int. 2012 [cited 2017 Jun 23];37(1):7-8. Available from: http://hi.llsl.br/detalhe_artigo. php?id=11775

14. Barreto JG, Guimarães LS, Frade MAC, Rosa PS, Salgado CG. High rates of undiagnosed leprosy and subclinical infection amongst school children in the Amazon Region. Mem Inst Osvaldo Cruz. 2012;107(suppl.I):60-7. doi: https:// doi.org/10.1590/S0074-02762012000900011

15. Barreto JG, Bisanzio D, Frade MAC, Moraes TMP, Gobbo AR, Guimarães LS, et al. Spatial epidemiology and serologic cohorts increase the early detection of leprosy. BMC Infect Dis. 2015;15:527. doi: https://doi.org/10.1186/ s12879-015-1254-8

16. Organização Pan-Americana de Saúde (BR) [Internet]. Brasília, DF: OPAS; c2016-2020 [citado 2017 set 23]. Projeot Palmas livre da hanseníase faz treinamento em serviço para profissionais do Programa Mais Médicos; [about 1 screen]. Available from: http://www.paho.org/bra/index. php?option=com_content $\&$ view $=$ article $\& i d=5226$ : projeto - palmas livre-da-hanseniase-faz-treinamento-em-servico-para-profissionais-doprograma-mais-medicos\&ltemid $=834$

17. Organização Pan-Americana de Saúde (BR) [Internet]. Brasília, DF: OPAS; c2017-2020 [cited 2020 Jun 18]. OPAS/OMS colabora com 0 Brasil para livrar país de hanseníase; [about 1 screen]. Available from: https://www.paho.org/bra/index.php?option=com_content\&view= article\&id=5474: opas-oms-colabora-com-brasil-para-livrar-pais-dahanseniase\&ltemid $=812$

18. Barreto JG, Frade MAC, Bernardes Filho F, Silva MB, Spencer JS, Salgado CG. Leprosy in children. Curr Infect Dis Rep. 2017;19(6):23. doi: https://doi. org/10.1007/s11908-017-0577-6 
19. Freitas BHBM, Cortela DCB, Ferreira SMB. Trend of leprosy in individuals under the age of 15 in Mato Grosso (Brazil), 2001-2013. Rev Saude Publica. 2017;51:28. doi: https://doi.org/10.1590/s1518-8787.2017051006884

20. Schneider PB, Freitas BHBM. Tendência da hanseníase em menores de 15 anos no Brasil, 2001-2016. Cad Saúde Pública. 2018;34(3):e00101817. doi: https:// doi.org/10.1590/0102-311x00101817

21. Ministério da Saúde (BR). Secretaria de Vigilância em Saúde. Departamento de Vigilância das Doenças Transmissíveis. Coordenação Geral de Hanseníase e Doenças em Eliminação. Informe Técnico e operacional "V Campanha Nacional de Hanseníase, Verminoses, Tracoma e Esquistossomose". Brasília: Ministério da Saúde; 2017 [cited 2019 Aug 20]. Available from: https://repositorio. observatoriodocuidado.org/bitstream/handle/handle/2101/Informe-T-cnico-e-Operacional---V-Campanha-Nacional-de-Hansen--ase-VerminosesTracoma-e-Esquistossomose.pdf? sequence $=1$ \&isAllowed $=\mathrm{y}$

\section{- Acknowledgments:}

To the coordination of the Leprosy Control Program of the State of Amapá for technical support in carrying out this work.

\section{- Authorship contribution:}

Conceptualization, methodology and writing - review and editing: Maria Eduarda de Macêdo Basso, Rosemary Ferreira de Andrade, Rodrigo Luís Ferreira da Silva.

Investigation and writing - original draft: Maria Eduarda de Macedo Basso.

The authors approved the final version of the manuscript and assume public responsibility for its content.

\section{- Corresponding author:}

Maria Eduarda de Macedo Basso

Email: eduardafisio2007@hotmail.com
22. Ministério da Saúde (BR). Secretaria de Vigilância em Saúde. Departamento de Doenças de Condições Crônicas e Infecções Sexualmente Transmissíveis. Hanseníase no Brasil: caracterização das incapacidades físicas. Brasília: Ministério da Saúde; 2020 [cited 2019 0ct 10]. Available from: http://www. aids.gov.br/system/tdf/pub/2016/67206/hanseniase_brasil_incapacidades_ fisicas_18fev20_web.pdf?fle $=1 \&$ type $=$ node\&id $=67206 \&$ force $=1$

23. Araújo KMFA, Leano HAM, Rodrigues RN, Bueno IC, Lana FCF. Epidemiological trends of leprosy in an endemic state. Rev Rene 2017; 18(6):771-8. doi: https:// doi.org/10.15253/2175-6783.2017000600010

24. Anchieta JJS, Costa LMM, Campos LC, Vieira MR, Mota OS, Morais Neto OL, etal. Trend analysis ofleprosyindicatorsin a hyperendemicBrazilian state, 2001-2015. RevSaúde Pública 2019;53:61. doi: https://doi.org/10.11606/s1518-8787.2019053000752

25. Lee J, Kim JP, Nishikiori N, Fine PEM. The decline of leprosy in the Republic of Korea; patterns and trends 1977-2013. Lepr Rev. 2015;86(4):316-27.

\section{Associate editor:}

Carlise Rigon Dalla Nora

Received: 01.27.2020

Approved: 09.22.2020

\section{Editor-in-chief:}

Maria da Graça Oliveira Crossetti 